\title{
Selected Harmonics Elimination for Modified Multilevel Inverter with Bi-Directional Switches
}

\author{
Ibrahim A. Muhammed \\ Department of Electrical Eng \\ University of Mosul \\ Mosul, Iraq
}

\author{
Mohamad N. Abdul Kadir \\ Department of Electrical Eng \\ University of Mosul \\ Mosul, Iraq
}

\begin{abstract}
Multilevel inverters are receiving continuous attention in terms of circuit topology, control methods and applications. This paper presents a modified topology that applies a bidirectional switching module to reduce the number of switches of the 3-level inverter. Common emitter back-toback IGBTs have been used to assemble the bidirectional conducting module. The modified inverter has been controlled using the selected harmonics eliminations technique with 3, 4 and 5 primary switching angles. The control algorithm has been implemented using a basic fixed point, low-cost microcontroller. Results including output voltage and current waveforms, spectrum, harmonic distortion, and converter efficiency data are presented. Simulation and experimental results verified the ability of the inverter to provide a wide range of output voltage and eliminate the targeted harmonics.
\end{abstract}

\section{General Terms}

Algorithm development, embedded system, power electronic.

\section{Keywords}

Multilevel Inverters, Voltage Control, Selected Harmonics Elimination.

\section{INTRODUCTION}

Multilevel inverter (MLI) is regarded as a reasonable option for high -to-medium voltage and power applications [1] [2] [3]. Among the advantages of MLI are less voltage distortion, lower device ratings, reduced input current distortion and $\mathrm{dv} / \mathrm{dt}$ stress. The MLI disadvantages, compared to the basic six-step inverter, are a large number of power semiconductor switches that results in more complexity and proneness to fault [4]. Increasing the number of levels enhances the MLI advantages. The increase of circuit complexity, however, limits the feasible number to few levels. In the literature, the most popular option of MLIs is the three-level inverter [5].

Being originals and distinctive, neutral point clamped (NPC), flying capacitor (FC) and cascaded H-bridge (CHB); topologies are defined as the basic MLI circuits [6] [7] [8]. These topologies, however, suffer from several limitations; particularly when designed with a higher number of levels. In this context, research has been conducted and many papers have been published trying to present innovative and improved designs [9] [10]. Most of the proposed work focus on reducing the switching devices count-to- the number of levels ratio [11] [12] [13]. Others attempt to replace diodes by active switches to provide more flexibility and enhance dc voltage balance [14], other studies introduced added elements to provide fault tolerant topologies [15] [16].

The circuit in Figure 1 has been introduced as a novel MLI design to reduce the number of switching devices of the threelevel inverter to 9 compared to 12 in the basic topologies [17]
[18] [19]. To control the converter a modified square wave mode has been presented as a low-frequency control scheme [17]. An SVPWM has also been presented for the same circuit as a high- quality control scheme [18]. A single-carrier, multilevel PWM scheme has been employed to generate the gating signals for the power switches [17]

The number of level of the design shown in Figure 1 is limited to 3-levels. A modified MLI that uses bi-directional switching devices and designed with an unrestricted number of levels has been presented. By using the circuit shown in Figure 1 with added circuitry. The added circuitry imposes limitations on the operation of bidirectional switches, which cancels some of the voltage levels. Special SVPWM has been developed for voltage control [13].

In this paper, the three-level inverter based on bidirectional switches has experimented with a modified implementation of bidirectional switch. The modification aims to reduce the converter voltage drop and therefore switching losses and enhance the voltage balance. The paper applies selective harmonics elimination (SHE) control in order to further improve load current quality and MLI efficiency.

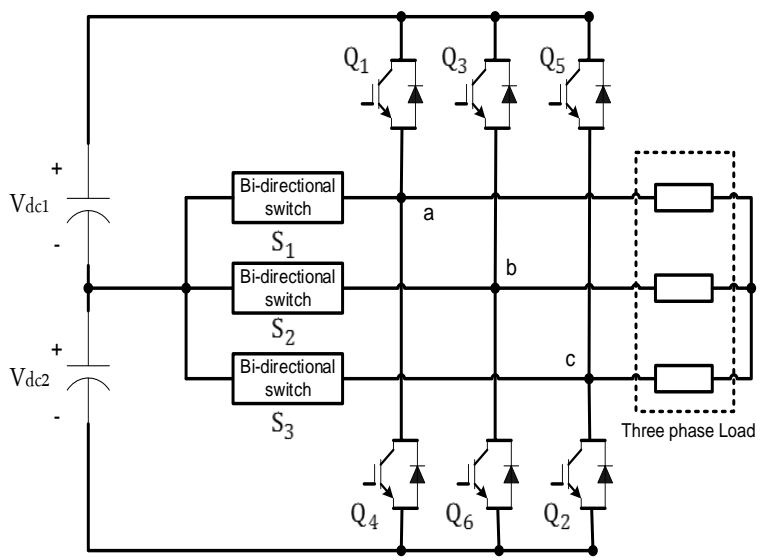

Fig 1: A three-level inverter with bidirectional switching devices.

This method, which is known for being computationally demanding, has been implemented using a low-cost microcontroller board.

The following section introduces the circuit topology and voltage equations and the formulation of control equations. Section III presents the numerical technique used to solve the equations and provide the switching tables for 3, 4 and 5 primary switching angles. Section IV presents the simulation and experimental results. The discussion and conclusion are presented in the last section. 


\section{CIRCUIT CONFIGURATION AND EQUATIONS FORMULATION}

This section presents the formulation of output line and phase equations as a function of the inverter switching state. Fourier analysis method is applied to define the expression of the general, $\mathrm{n}^{\text {th }}$, harmonic.

\subsection{Bidirectional Switching Modules}

In order to build the modified MLI, bidirectional switches are required that are capable of blocking voltage and conducting current in both directions. Unfortunately, such devices are currently not available as a single element. To fulfill these requirements, bidirectional switch modules are assembled using discrete switching devices. The four types of bidirectional switch arrangements commonly known are shown in Figure 2 [20]

In previous studies, the configuration of Figure 2(a) has been applied in the three-level inverter circuit shown in Figure 1 [11], [12], [13] and [21]. This configuration suffers from a high voltage drop that produces high conduction losses and voltage imbalance. In this work, however, it has been elected to use the configuration of Figure 2(b) to mitigate the effect of the switch voltage drop.

\subsection{Three-Phase Three-Level Nine- Switches Multilevel Inverter}

The three-level inverter shown in Figure 1 has been constructed. The bidirectional modules $\left(\mathrm{S}_{1}, \mathrm{~S}_{2}\right.$, and $\left.\mathrm{S}_{3}\right)$ design is shown in Figure 2(b). When operating in square wave mode, the unidirectional switches $\left(\mathrm{Q}_{1}-\mathrm{Q}_{6}\right)$ operate at the fundamental frequency; while the bidirectional switches $\left(\mathrm{S}_{1}\right.$ $\mathrm{S}_{3}$ ) operate at a twice fundamental frequency. The square wave control method of creating output waveforms has simple control circuitry and operate at a low switching frequency to obtain minimum switching losses and voltage stress [11].

When using two equal dc sources with a common point, each phase can be independently operated. However, just like NPC and FC inverters; the two dc sources can be replaced by a capacitor voltage divider. In this case, the controller must maintain the voltage balance of the capacitors [17]

The control variables of the three inverter branches a, b, and c are denoted by $k_{a}, k_{b}$, and $k_{c}$ respectively, where, $k_{a}, k_{b}$, and $k_{c}$ $\in[-1,0,1]$. The impact of changing a switching variable is explained in Figure 3. The corresponding line and phase voltages are given in Equations (1) and (2).

$$
\begin{aligned}
& {\left[\begin{array}{l}
V_{a b} \\
V_{b c} \\
V_{c a}
\end{array}\right]=V_{s}\left[\begin{array}{ccc}
1 & -1 & 0 \\
0 & 1 & -1 \\
-1 & 0 & 1
\end{array}\right]\left[\begin{array}{l}
k_{a} \\
k_{b} \\
k_{c}
\end{array}\right]} \\
& {\left[\begin{array}{l}
V_{a n} \\
V_{b n} \\
V_{c n}
\end{array}\right]=\frac{V_{s}}{3}\left[\begin{array}{ccc}
2 & -1 & -1 \\
-1 & 2 & -1 \\
-1 & -1 & 2
\end{array}\right]\left[\begin{array}{l}
k_{a} \\
k_{b} \\
k_{c}
\end{array}\right]}
\end{aligned}
$$

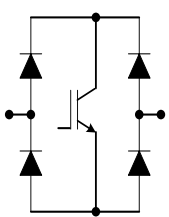

(a)

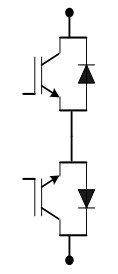

(b)

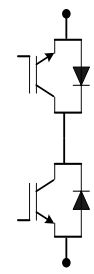

(c)

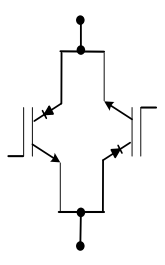

(d)
Fig 2: Bi-directional switch arrangements (a) Diode bridge (b) Common emitter back-to-back (c) Common collector back-to-back (d) anti-paralleled reverse blocking IGBTs.

Equations (1) and (2) show that the output voltages are linearly proportional to the switching variables.

\subsection{Formulation of SHE Equations}

The linear relationship between the line and phase voltages and the switching variables in the Equations (1) and (2) implies that the various harmonics in the output voltages are reflections of the Fourier component of the switching function. This is correct with exception of the triple harmonics which appear in common mode in the three output lines and therefore eliminate each other. The switching functions applied in this research have 3, 4 or 5 independent switching angles. Figure 4 shows the switching a function with 3 independent switching angles. This Figure implies that the average switching frequency is equivalent to the fundamental frequency times the number of primary switching angles. Where the $\left(\mathrm{Q}_{1}-\mathrm{Q}_{6}\right)$ operate at this frequency, and $\left(\mathrm{S}_{1}-\mathrm{S}_{3}\right)$ operate at twice this value.

The switching function is quarter-wave symmetrical, therefore the Fourier series expansion of the output voltage $V_{a 0}$ shown in Figure 4, can be expressed as:

$$
\begin{aligned}
& B_{n}=\frac{4}{n \pi} \sum_{i=1}^{m}(-1)^{i+1} \cos \left(n \theta_{i}\right) \text { Type equation here.(3) } \\
& V_{a 0}(\omega t)=\sum_{i=1,3,5, . .} B_{n} \sin (n \omega t)
\end{aligned}
$$

Where $B$ is the sine Fourier coefficient; $n$ represents the harmonic order $(n=1,3,5 \ldots)$ and $m$ is the number of primary switching angles.

The switching angles, for the first case $\left(\theta_{1}, \theta_{2}\right.$, and $\left.\theta_{3}\right)$, must be determined to eliminate the first two $(m-1)$ odd non-triple harmonic components $\left(5^{\text {th }}\right.$ and $\left.7^{\text {th }}\right)$.

$$
\begin{aligned}
& \cos \left(\theta_{1}\right)-\cos \left(\theta_{2}\right)+\cos \left(\theta_{3}\right)=\frac{\pi}{4} M I \\
& \cos \left(5 * \theta_{1}\right)-\cos \left(5 * \theta_{2}\right)+\cos \left(5 * \theta_{3}\right)=0 \\
& \cos \left(7 * \theta_{1}\right)-\cos \left(7 * \theta_{2}\right)+\cos \left(7 * \theta_{3}\right)=0
\end{aligned}
$$

$M I$ is the modulation index defined as:

$M I=\frac{h_{1}}{V_{S}}$

and:

$\theta_{1}<\theta_{2}<\theta_{3}<\frac{\pi}{2}$

\section{SIMULATION RESULTS}

This section presents the results of computer calculations and simulation. Firstly, the solution of non-linear equations (1-9) is described. Then simulation is shown to evaluate the performance of the system.

\subsection{Determination of Switching Tables}

Equations (5-7) and their analogies for 4 and 5 primary switching angles are highly nonlinear and can only be solved numerically. To find the angles $\left(\theta_{1}, \theta_{2}, \theta_{3}\right.$, etc.) and hence the switching signals, the Newton-Raphson method has been applied. The solution has been repeated after fixed steps increments of modulation index, $M I$ to obtain the switching lookup tables. Newton-Raphson method works efficiently with reasonable initial estimations $\left(\theta_{1}^{0}, \theta_{2}^{0}\right.$, and $\left.\theta_{3}^{0}\right)$ and this can be effectively satisfied considering the constraints described in equation (9). Nonlinear equations (5-7) and their derivatives have been rearranged in the forms given by equations (10-12), and Newton Raphson's next approximation 
is given by equations (13 and 14) as follows:

$$
\begin{aligned}
& T=\left[\begin{array}{c}
M I * \pi / 4 \\
0 \\
0
\end{array}\right] \\
& F=\left[\begin{array}{c}
\cos \left(\theta_{1}\right)-\cos \left(\theta_{2}\right)+\cos \left(\theta_{3}\right) \\
\cos \left(5 * \theta_{1}\right)-\cos \left(5 * \theta_{2}\right)+\cos \left(5 * \theta_{3}\right) \\
\cos \left(7 * \theta_{1}\right)-\cos \left(7 * \theta_{2}\right)+\cos \left(7 * \theta_{3}\right)
\end{array}\right]
\end{aligned}
$$
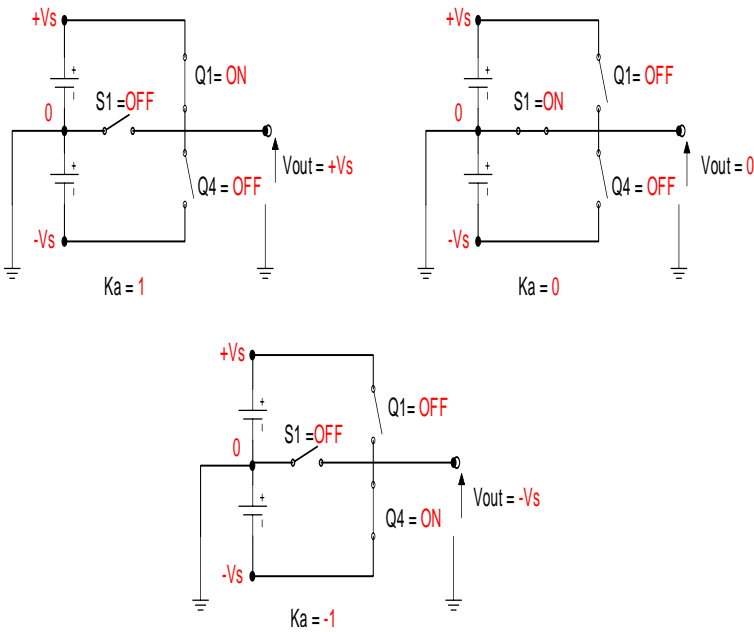

Fig 3: The three states of the switches per phase for threelevel modified inverter.

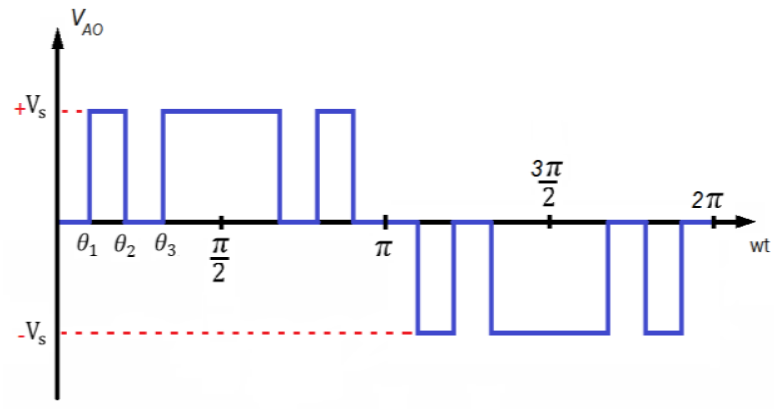

Fig 4: Phase to the midpoint output voltage.

$f=\left[\begin{array}{ccc}-\sin \left(\theta_{1}\right) & +\sin \left(\theta_{2}\right) & -\sin \left(\theta_{3}\right) \\ -5 * \sin \left(5 * \theta_{1}\right) & +5 * \sin \left(5 * \theta_{2}\right) & -5 * \sin \left(5 * \theta_{3}\right) \\ -7 * \sin \left(7 * \theta_{1}\right) & +7 * \sin \left(7 * \theta_{2}\right) & -7 * \sin \left(7 * \theta_{3}\right)\end{array}\right]$

$d \theta=(\operatorname{inv}(f)) *(T-F)$

$\theta_{n+1}=\theta_{n}+d \theta_{n}$

Equations (10-14) have been solved for the entire range of MI. Extended similar equations for the cases of 4 and 5 primary switching angles have been also solved and the results are shown in Figure 5.

\subsection{Inverter Simulation}

The implementation of the switching angles to control the three-level inverter under investigation has been modeled. The simulation included the power circuit besides the controlled and executed on Simulink $®$ graphical programming environment. Figure 6 shows the simulated circuit.

With $M I=1.0$ and with 3, 4 and 5 primary switching angles, the simulation results of the output line voltages are shown in
Figures (7), (8) and (9) respectively. These Figures also show the spectrum of the three voltages to confirm the elimination of the targeted harmonics in each case. Line voltage of the inverter at different modulation index and with passive RL load is shown in Figure 10. The circuit has been also simulated with induction motor load. Figure 11 shows the resultant line voltage and phase current.

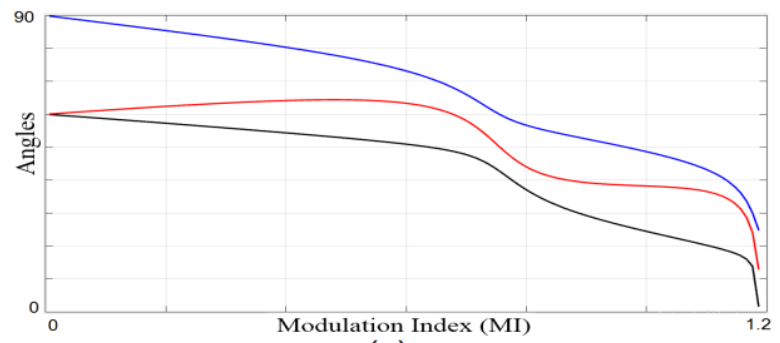

(a)

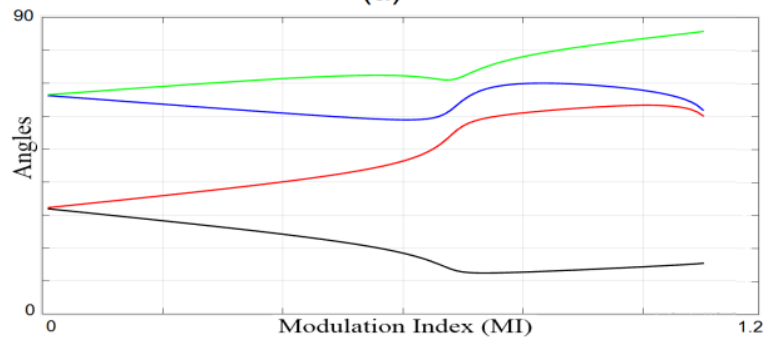

(b)

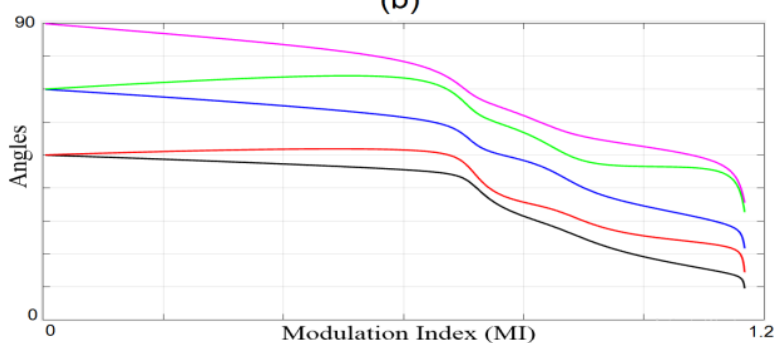

(c)

Fig 5: Calculated switching angles over the entire range of modulation index (a) 3 switching angles; (b) 4 switching angles; (c) 5 switching angles.

Figure 12 shows the Total Harmonic Distortion (THD) of RL load current when the inverter operated with 3,4 and 5 angles and variable load power factor. The odd number of angels (3 and 5) provide lower THD compared to even number (4).

The efficiency of the inverter has been determined as the ratio between the average input-to-output power of the inverter and with 3,4 , and 5 primary switching angles and the entire range of modulation index. The results are shown in Figure 13. This Figure shows that the number of switching angles has a negligible effect on efficiency as the converter losses are mainly conduction losses.

\section{INVERTER IMPLEMENTATION AND EXPERIMENTAL RESULTS}

For experimental verification, a prototype has been constructed with the following parameters:

The DC supply voltage $=100 \mathrm{~V}$

The load is $\mathrm{Y}$-connected a $42 \Omega$ resistor with $589 \mathrm{mH}$ inductor per phase.

At the testing frequency, this RL load power factor is 0.225 . The control program is implemented using the Arduino Uno 
microcontroller board based on the ATmega328P. The lookup table is stored in the board $32 \mathrm{~KB}$ flash memory and the reference signal (modulation index and reference frequency) is transmitted to the board through the USB connection. Out of the 14 digital I/O pins, 9 have been used to transmit the switching signals to the gate drives of the switching devices. Figure 14 shows the hardware power switches and drives.

Measured line voltages for the three modes of 3, 4 and 5 angles are shown in Figures $(15,16$ and 17) respectively. The frequency spectra of the measured voltages are also shown to show the elimination of the low order harmonics.

Current measurement together with phase voltage is shown in Figure 18 for inverter operating with 5 primary angles. $1 \Omega$ shunt thermal resistor is used to perform the current measurement.

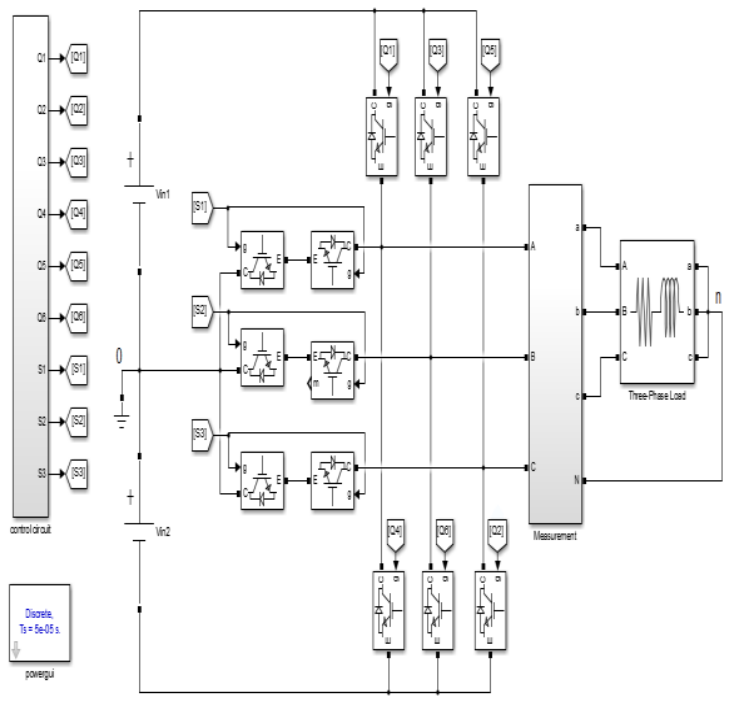

Fig 6: simulated circuit using Matlab program with RL load and SHE technique for firing angles.

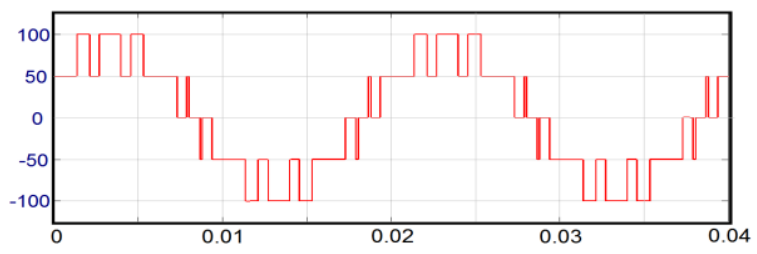

(a)

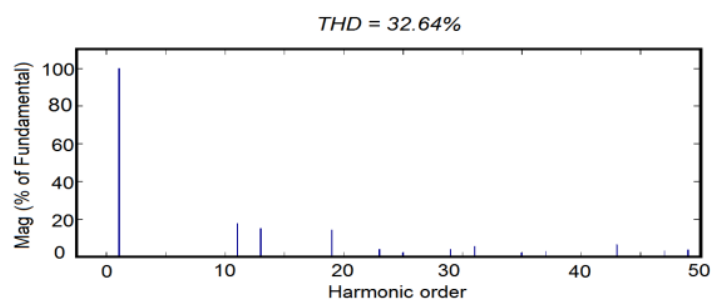

(b)

Fig 7: Simulated three switching angles, modulation index, m=1(a) line voltage; (b) FFT spectrum.

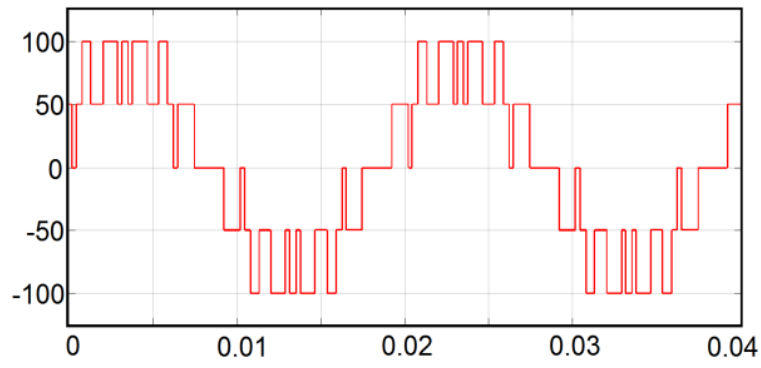

(a)

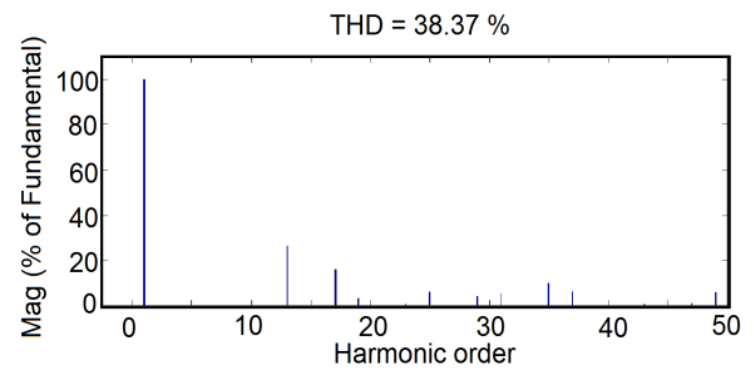

(b)

Fig 8: Simulated four switching angles modulation index, m=1 (a) line voltage; (b) FFT spectrum.

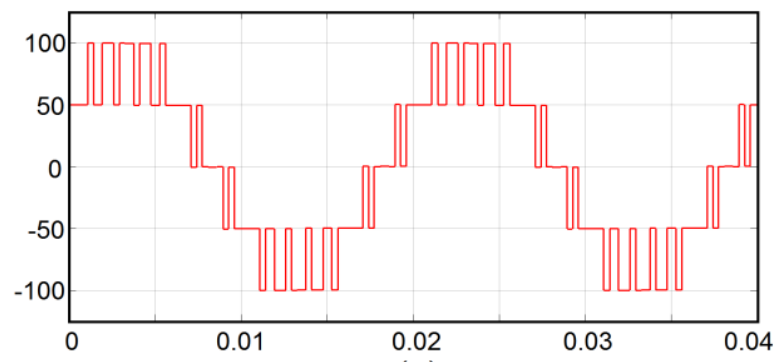

(a)

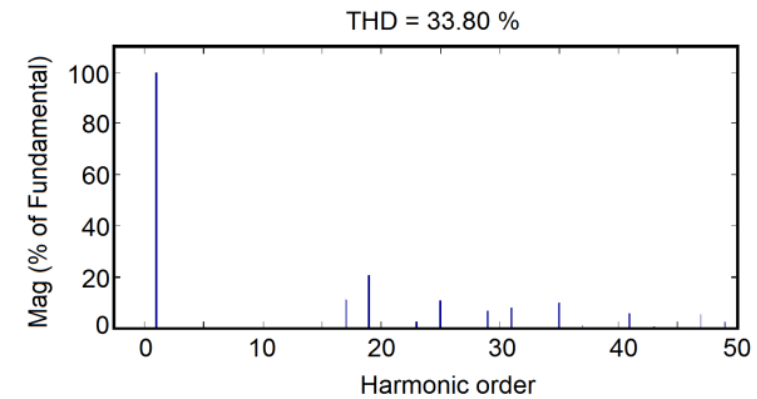

(b)

Fig 9: Simulated Five switching angles modulation index, m=1 (a) line voltage; (b) FFT spectrum. 

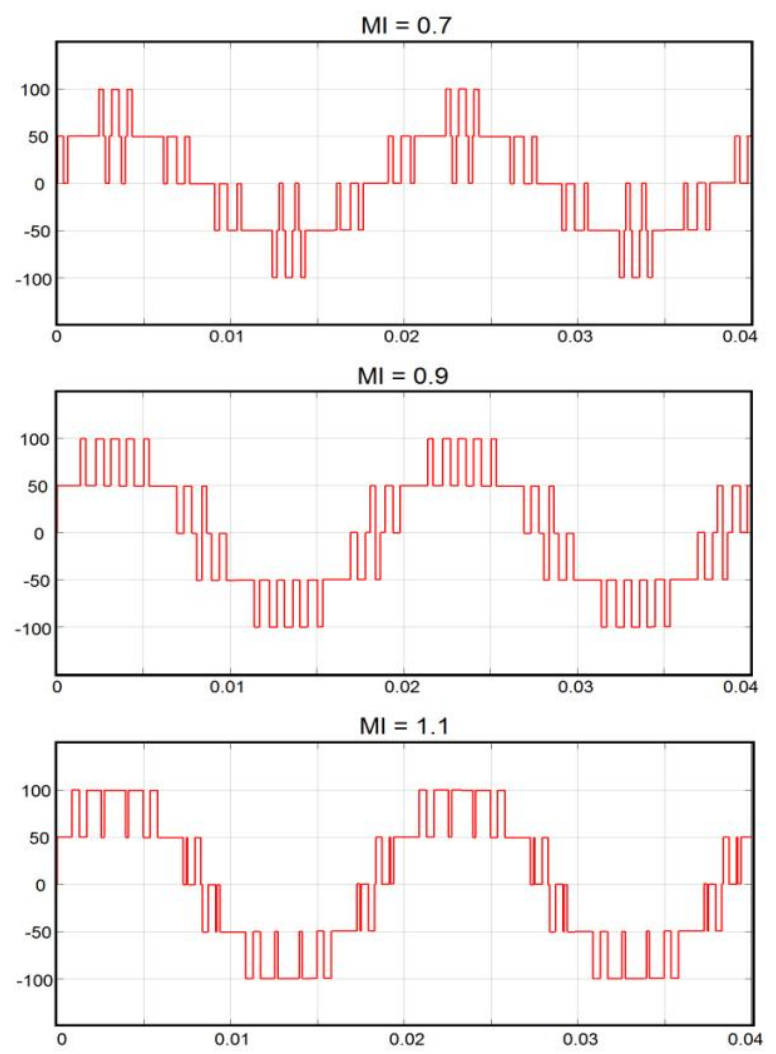

Fig 10: Simulated line voltage using five switching angles with different modulation index.

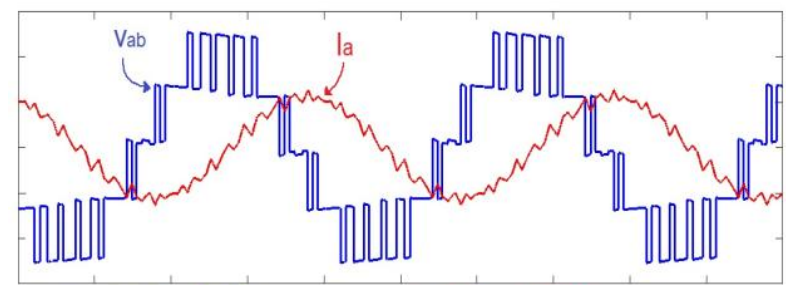

$\mathrm{Vab} \mathrm{THD}=34.6 \%$

la $\mathrm{THD}=10.28 \%$

Fig 11: Line voltage and phase current of induction motor supplied by the proposed inverter.

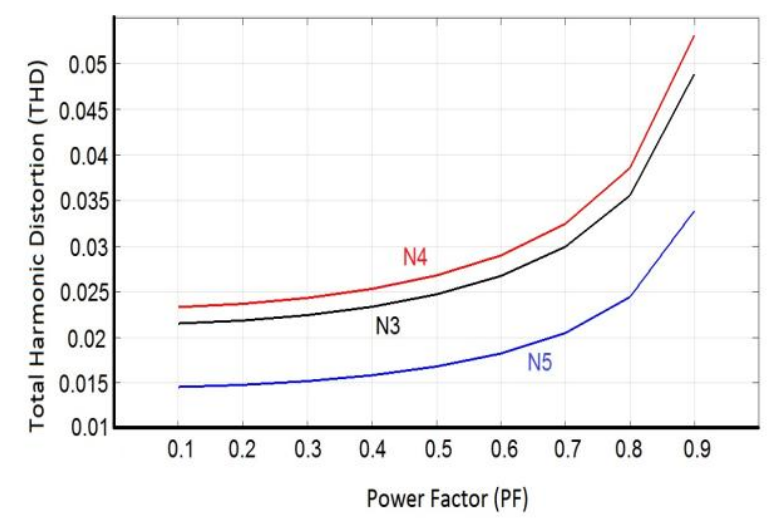

Fig 12: Total Harmonic Distortion of the output current for 3, 4 and 5 angles mode against the load PF.

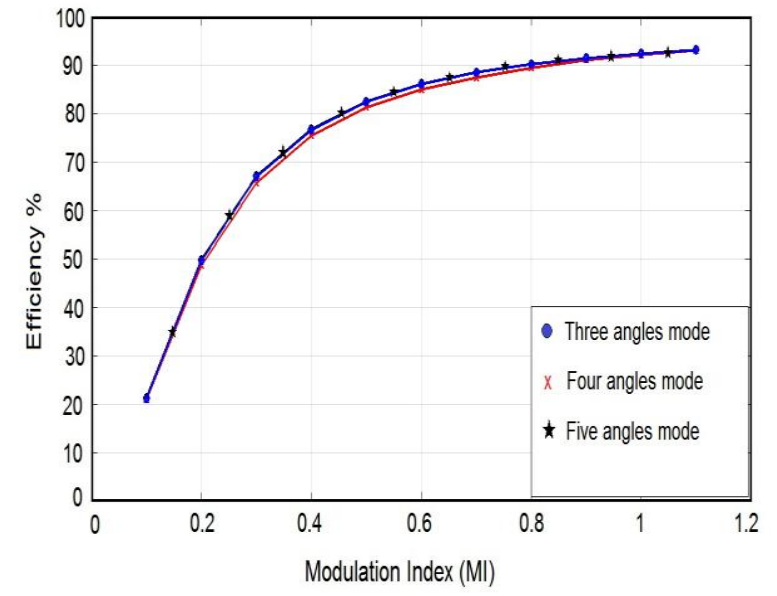

Fig 13: The efficiency of the inverter at different Modulation Index.
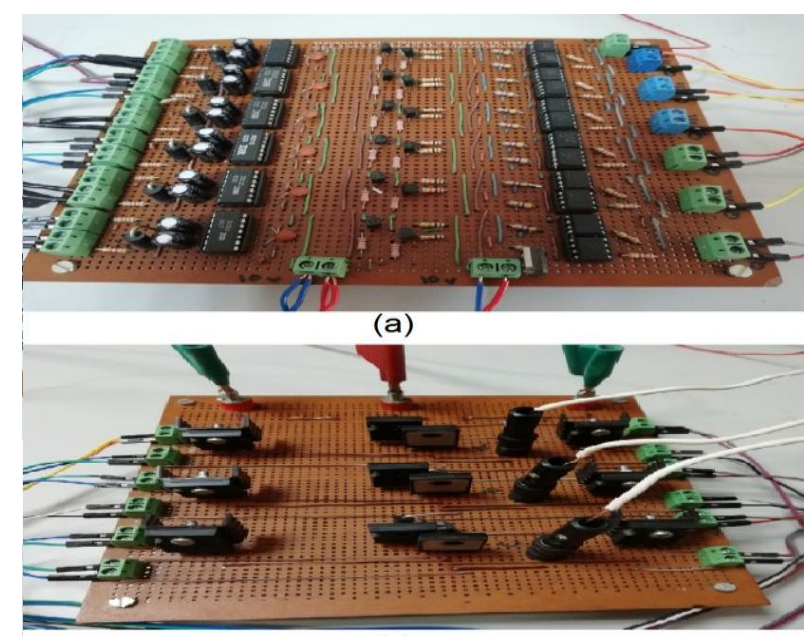

(b)

Fig 14: (a) Drive circuit (both Opto-Coupler and IR2110); (b) Three phase modified multilevel inverter.

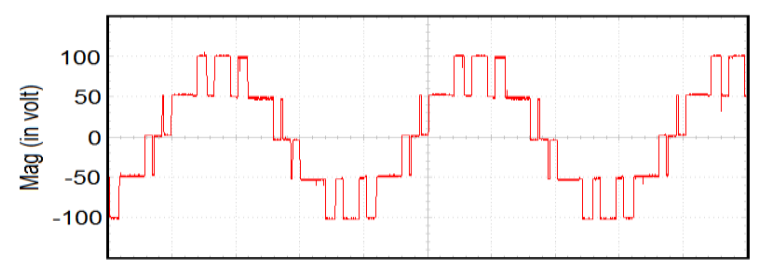

(a)

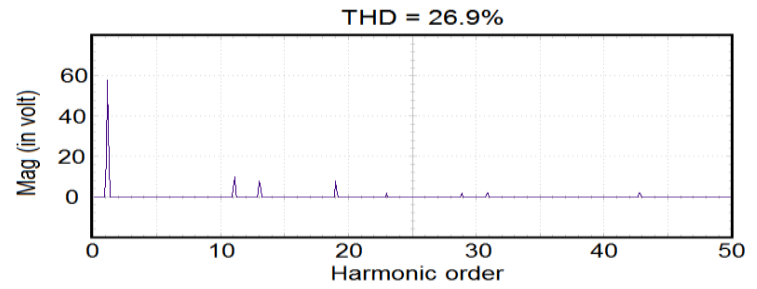

(b)

Fig 15: Measured three switching angles (a) line voltage; (b) FFT spectrum. 


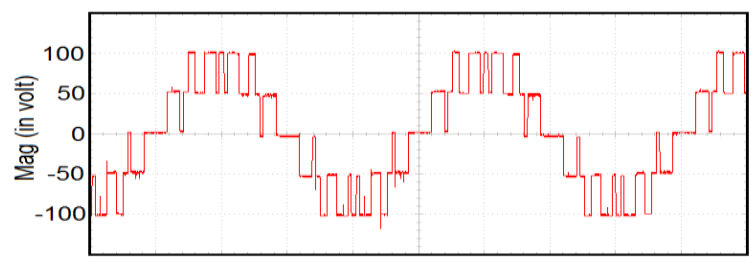

(a)

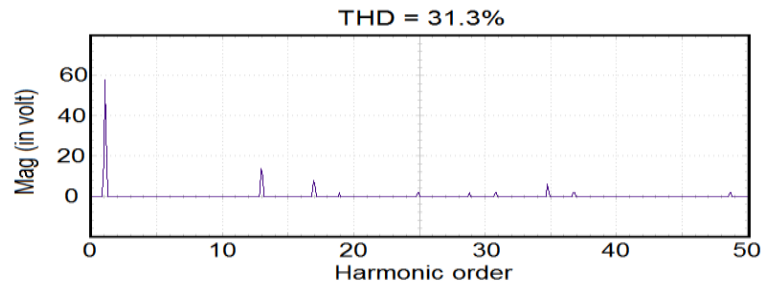

(b)

Fig 16: Measured four switching angles (a) line voltage; (b) FFT spectrum.

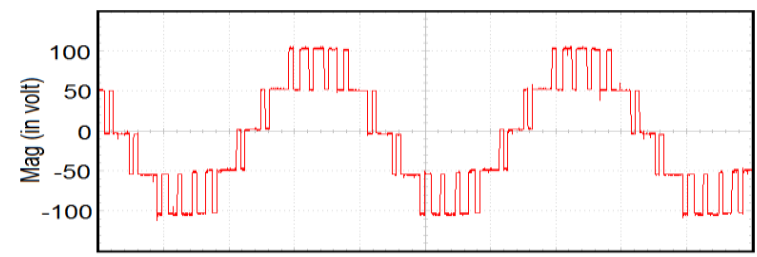

(a)

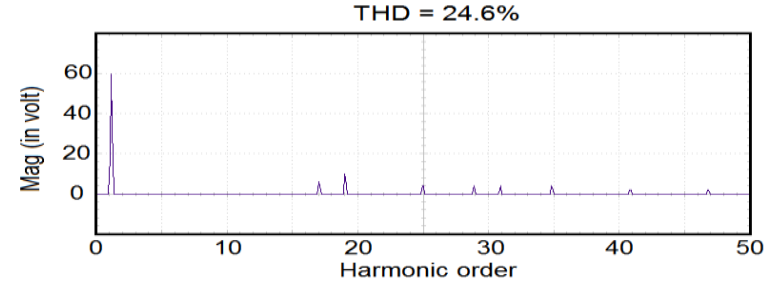

(b)

Fig 17: Measured five switching angles (a) line voltage; (b) FFT spectrum.

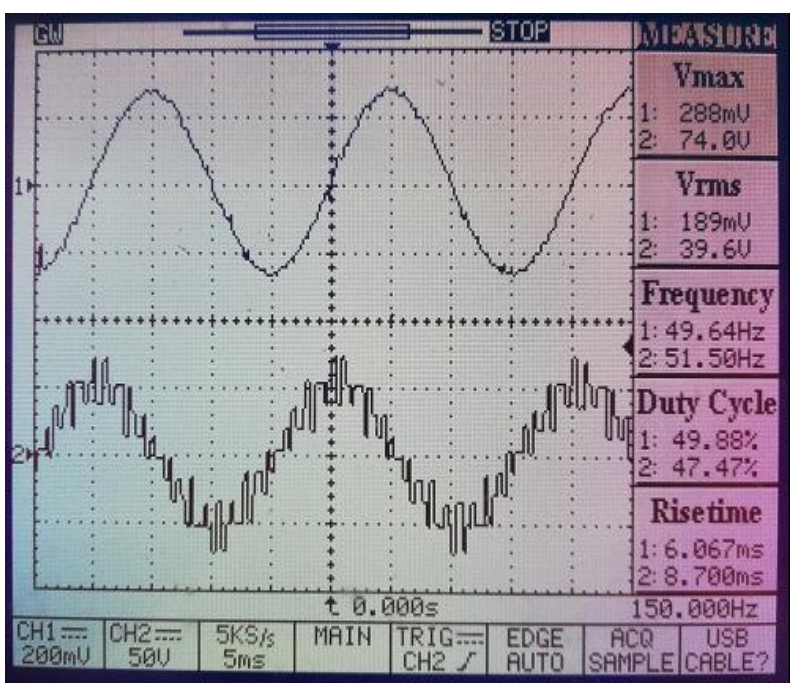

Fig 18: The top is output phase current and below is output phase voltage.

\section{DISCUSSION AND CONCLUSION}

This paper presents the design and implementation of a threelevel inverter designed with modified topology using bidirectional switching modules. The use of bidirectional switches provides two advantages. First, the switching devices of the bidirectional module have the same switching signal and the gate drive circuit which simplifies the circuit. Secondly, this circuit is inherently tolerant to faults in bidirectional switches as it can be operated under fault condition as a conventional 2-level inverter.

The numerical method used to solve non-linear equations has been described. This work presents the switching state based3 representation. The straightforward relationship between the switching function and the output voltages has been used to mitigate the solution of the nonlinear equations and the controller implementation.

The SHE control method is known for its computational burden, yet the lookup table technique applied in this work has proven that a multilevel-PWM can be efficiently implemented using one of the simplest microcontroller boards available. The key in the effective and creative exploitation of the board resources.

Simulation and experimental results of the proposed inverter show that the low order harmonics have been effectively eliminated. It has been demonstrated that the THD of the load current is below $6 \%$ and $4 \%$ for load power factor and 0.9 and 0.8 respectively. The inverter efficiency is higher than $80 \%$ for modulation index $0.5<\mathrm{MI}<1.1$ It is also noticed that the THD of the output voltage slightly increases with four primary switching angle. This is due to the notch in the middle of the positive pulse. Simulation and experimental results verify that the proposed system meets the design targets of nulling the most distorting harmonics and controlling the fundamental component

\section{REFERENCES}

[1] Rodríguez, J.; Morán, L.; Pontt, J.; Hernández, J.L.; Silva, L.; Silva, C.; and Lezana, P. (2002). High-Voltage Multilevel Converter With Regeneration Capability. IEEE TRANSACTIONS ON INDUSTRIAL ELECTRONICS, 49(4).

[2] Hosoda, H.; and Peak, S. (2010). Multi-Level Converters for Large Capacity Motor Drive. The 2010 International Power Electronics Conference.

[3] Rodríguez, J.; Bernet, S.; Wu, B.; Pontt, J.O.; and Kouro, S. (2007). Multilevel Voltage-Source-Converter Topologies for Industrial Medium-Voltage Drives. IEEE TRANSACTIONS ON INDUSTRIAL ELECTRONICS, 54( 6).

[4] Rao, N.M.; Reddy, D.R.; and Jayakrishina, G. (2016). Large-Scale Grid-Connected Photovoltaic Systems using Cascaded Modular Multilevel Converters for Decoupled Active and Reactive Power Control. International Journal of Advanced Technology and Innovative Research, 08(21), 4066-4071.

[5] Avci, E.; and Ucar, M. (2017). Analysis and design of grid-connected 3-phase 3-level AT-NPC inverter for low-voltage applications. Turkish Journal of Electrical Engineering \& Computer Sciences, 25, 2464 -2478.

[6] Ozdemir, E.; Ozdemir, S.; and Tolbert, L.M. (2009). Fundamental-Frequency-Modulated Six-Level DiodeClamped Multilevel Inverter for Three-Phase Stand- 
Alone Photovoltaic System. IEEE TRANSACTIONS ON INDUSTRIAL ELECTRONICS, 56(11).

[7] Huang, J.; and Corzine, K.A. (2006). Extended Operation of Flying Capacitor Multilevel Inverters. IEEE TRANSACTIONS ON POWER ELECTRONICS, 21(1).

[8] Villanueva, E,; Correa, P.; Rodríguez, J.; and Pacas, M. (2009). Control of a Single-Phase Cascaded H-Bridge Multilevel Inverter for Grid-Connected Photovoltaic Systems. IEEE TRANSACTIONS ON INDUSTRIAL ELECTRONICS, 56(11)

[9] Abirami, R.; Chellammal, N.; Dash, S.S.; and Velmurugan, V. (2013). Multicarrier Pulse Width Modulation Based Hybrid Multilevel Inverter. Proc. of Int. Conf. on Control, Communication and Power Engineering. published by Elsevier Academic Press.

[10] Hasan, M.; Mekhilef, S.; and Ahmed, M. (2014). Threephase hybrid multilevel inverter with less power electronic components using space vector modulation. IET Power Electronics, 7(5), 1256-1265.

[11] Mahrous, E.A.; Rahim, N.A.; and Hew, W.P. (2006). Analysis Design and Simulation of a Three-Phase ThreeLevel Nine Switches-Inverter Using Space Vector Modulation. The 6th International Workshop on System on Chip for Real-Time Applications. Cairo, Egypt.

[12] Balakrishnan, D.; and Shanmugam, D. (2013). Modified Multilevel Inverter Topology with Reduced Switch Count and a Novel PWM Control Scheme. International Journal of Scientific and Research Publications, 3(11).

[13] Jamaludin, J.; Abd Rahim, N.; and Ping, H.W. (2013). An 11-Switch Multilevel Inverter With a Modified Space Vector Modulation. Turkish Journal of Electrical
Engineering \& Computer Sciences, 24, 171 - 183.

[14] Brückner, T.; Bernet, S.; and Güldner, H. (2005). The Active NPC Converter and Its Loss-Balancing Control. IEEE TRANSACTIONS ON INDUSTRIAL ELECTRONICS, 52(3).

[15] Jalhotra, M.; Kumar, L.; Gautam, S.P.; and Gupta, S. (2018). Development of fault-tolerant MLI topology. IET Power Electronics.

[16] Gautam, S.P.; Gupta, S.; and Kumar, L. (2017). Reliability improvement of transistor clamped H-bridgebased cascaded multilevel inverter. IET Power Electronics, 10(7), 770-781.

[17] Odeh, C.I. (2015). Improved Three-Phase Five-Level PWM Switched Voltage Source Inverter. IET Power Electronics, 8(4), 524-535.

[18] Park, S.J.; Kang, F.S.; Lee, M.H.; and Kim, C.U. (2003). A New Single-Phase Five-Level PWM Inverter Employing a Deadbeat Control Scheme. IEEE TRANSACTIONS ON POWER ELECTRONICS, 18(3).

[19] Tuluhong, A.; Wang, W.; Li, Y.; and Xu, L. (2018). A Novel Hybrid T-Type Three-Level Inverter Based on SVPWM for PV Application. Journal of Electrical and Computer Engineering, 2018(9), 1- 12.

[20] Lee, M.Y. (2009). Three-Level Neutral-Point Clamped Matrix Converter Topology. PhD thesis, University of Nottingham.

[21] Subramanian, D.; and Rasheed, R. (2013). Modified Multilevel Inverter Topology for Driving a Single Phase Induction Motor. International Journal of Advanced Research in Electrical, Electronics and Instrumentation Engineering, 2(1). 